\title{
Increased ratio of dietary carbohydrate to protein shifts the focus of metabolic signaling from skeletal muscle to adipose
}

Suzanne Devkota ${ }^{1,2}$, Donald K Layman ${ }^{3,4^{*}}$

\begin{abstract}
Background: The Dietary Reference Intakes (DRI) established acceptable macronutrient distribution ranges (AMDR) for carbohydrates and protein, however little is known about differences in glycemic regulations and metabolic signaling across this range. This study examined metabolic outcomes associated with intake of two diets differing in carbohydrate:protein ratios representing the upper and lower ends of the AMDR.

Methods: Adult, male rats were fed either a high carbohydrate $(\mathrm{CHO})$ diet (60\% of energy from carbohydrates, $12 \%$ protein, $28 \%$ fat; $n=30$ ) or a high protein $(P R O)$ diet (35\% carbohydrate, $35 \%$ protein, $30 \%$ fat; $n=30$ ). Rats were meal-fed $3 \mathrm{x} / \mathrm{d}$ the respective diets for $10 \mathrm{~d}$ and then terminated after overnight food deprivation or 30, 60, 90, 120 min post-prandial (PP). Plasma was collected at each of these points to provide a time course for glucose, insulin and C-peptide. Skeletal muscle and adipose tissues were collected at 0, 30 and 90 min for measurements of basal, early and delayed activation of Akt, p70S6K and Erk 1/2. Data were analyzed by two-way ANOVA.

Results: The $\mathrm{CHO}$ group produced a consistently elevated response in plasma glucose, insulin and C-peptide following the meal through the 120 min time course. In addition, Akt and Erk 1/2 activation in adipose was much higher than in skeletal muscle. Conversely, the PRO group PP glucose response was minimal and insulin maintained a response similar to a biphasic pattern. Tissue responses for the PRO group were greater for Akt and p70S6K signaling in skeletal muscle compared with adipose.
\end{abstract}

Conclusion: Taken together these data suggest that altering CHO:PRO ratios within the AMDR produce different glycemic response patterns accompanied by differential metabolic signaling in skeletal muscle and adipose.

\section{Background}

In the context of the rising incidence of insulin resistance, obesity, and cancer more attention has become focused on improving glycemic control, specifically insulin responsiveness, through altering dietary macronutrient ratios [1,2]. The current Dietary Reference Intakes (DRI) establish a wide range of acceptable macronutrient distributions (AMDR) for carbohydrates, protein, and fat, however very little is known about the effects of these ranges on metabolic regulations and specifically on insulin signaling in skeletal muscle and adipose. However, the wide ranges of potential macronutrient ratios would be expected to produce different insulin

\footnotetext{
* Correspondence: dlayman@illinois.edu

${ }^{3}$ Division of Nutritional Sciences, University of Illinois, Urbana, IL 61801, USA
} Full list of author information is available at the end of the article responses following a meal $[3,4]$. Previous studies suggest that decreasing the dietary carbohydrate:protein ratio within the recommended DRI guidelines improves overall glucose homeostasis and insulin responsiveness $[1,2]$, but it is unclear how peripheral metabolic tissues adapt to and mediate this response.

We propose that short-term dietary alterations in carbohydrate:protein ratios fed to phenotypically normal, lean adult rats will produce changes in insulin-mediated intracellular signal pathways - namely the metabolic arm signaling through Akt and p70S6K, and the mitogenic arm signaling through Erk1/2. Investigation into both pathways is supported by previous data in both animal and human studies that have shown altered glycogen metabolism and glucose disposal when fed differing ratios of carbohydrates, protein and fat $[5,6]$, as well as changes in adipogenesis [7]. Furthermore, we suggest

\section{C) Biomed Central}


that these metabolic changes have a differential response in skeletal muscle and adipose dependent upon carbohydrate load. While both tissues dispose of dietary glucose, they utilize glucose for different metabolic and mitogenic purposes and likely possess different adaptive capabilities.

We developed two isoenergetic test diets with different ratios of carbohydrate:protein representing the DRI guidelines for AMDR [8]. The high carbohydrate:protein ratio diet represents the upper end of the DRI range for carbohydrate intake and the lower end of the protein range and is similar to the typical carbohydrate intake in a Western diet [9]. The reduced carbohydrate:protein diet represents the lower end of the DRI range for carbohydrates and the upper end of the protein range. Previous studies have shown that diets with this composition of reduced carbohydrate:protein ratio enhance glycemic regulations [10]. This study examines the effects of these diets on glycemic regulations including glucose, insulin and $\mathrm{C}$-peptide concentrations and phosphorylation activation of Akt, p70S6K, and Erk1/2 as key regulatory markers of insulin signaling in skeletal muscle and adipose.

\section{Materials and methods}

\section{Animals and Feeding Protocol}

Male Sprague-Dawley rats $(274.7 \pm 1.5$ g; Harlan-Teklad, Indianapolis, IN) were maintained at $24{ }^{\circ} \mathrm{C}$ in $12 \mathrm{~h}$ light: dark cycle with free access to water. Rats were trained to meal-feed $3 \mathrm{x} / \mathrm{d}$ consuming either a diet with a high carbohydrate:protein ratio (CHO group) or a diet with a low carbohydrate:protein ratio (PRO group). Treatments were isoenergetic and designed to represent DRI ranges for acceptable macronutrient intakes. Treatments consisted of either $60 \%$ of energy from carbohydrate, $12 \%$ protein and $28 \%$ fat ( $\mathrm{n}=30$; $\mathrm{CHO}$ group) or $35 \%$ carbohydrate, $35 \%$ protein and $30 \%$ fat ( $n=30$; PRO group) (Table 1). The meal pattern consisted of a $4 \mathrm{~g}$ breakfast meal (20\% of total energy) consumed between 0700 0720, followed by free access to food between 1300 to

\section{Table 1 Diet composition of the $\mathrm{CHO}$ and PRO diets}

\begin{tabular}{lcccc}
\hline \multicolumn{1}{c}{ Component } & \multicolumn{2}{c}{ CHO Group } & \multicolumn{2}{c}{ PRO Group } \\
& $\boldsymbol{g} / \mathbf{k g}$ & \% energy & $\boldsymbol{g} / \mathbf{k g}$ & \% energy \\
\hline Whey & 128.33 & 12.0 & 379.78 & 35.0 \\
Cornstarch & 401.04 & 37.5 & 237.36 & 21.9 \\
Maltodextrin & 137.96 & 12.9 & 81.65 & 7.5 \\
Sucrose & 102.67 & 9.6 & 60.77 & 5.6 \\
Soybean oil & 133.03 & 28.0 & 144.48 & 30.0 \\
Cellulose (fiber) & 53.70 & & 3.70 & \\
Mineral mix & 37.60 & & 37.60 & \\
Vitamin mix & 10.70 & & 10.70 & \\
Choline bitartrate $^{1}$ & 2.70 & & 2.70 & \\
\hline
\end{tabular}

${ }^{1}$ AIN-93 mineral and vitamin supplements from Harlan-Teklad.
1400 ( 40\% total energy) and 1800 to 1900 ( 40\% total energy). This feeding pattern was designed to mimic human eating behavior [5]. To assess early metabolic changes, diets were fed for $10 \mathrm{~d}$ and rats were terminated by guillotine at 5 time points: prior to the $4 \mathrm{~g}$ breakfast meal, and 30, 60, 90 and 120 min following the 4 g breakfast meal ( $n=6 /$ time point). Trunk blood was collected at each time point, and liver, gastrocnemius, plantaris, and retroperitoneal fat pads were excised at 0, 30 and $90 \mathrm{~min}$ and immediately frozen in liquid nitrogen. Animal protocol was approved by the University of Illinois Institutional Animal Care and Use Committee.

\section{Plasma Analysis}

Plasma insulin and C-peptide were measured using commercial RIA kits (Millipore, St. Charles, MO) specific for rat. Plasma glucose was measured using a glucose oxidase/peroxidase method (Invitrogen, Carlsbad, CA).

\section{Tissue Preparation}

Plantaris and adipose were pulverized in liquid nitrogen and homogenized in $2 \mathrm{ml}$ ice cold lysis buffer using a Polytron homogenizer for $30 \mathrm{~s}$. Samples were centrifuged at $10,000 \times \mathrm{g}$ for $10 \mathrm{~min}$ at $4^{\circ} \mathrm{C}$. The supernatant was collected, aliquoted and stored in $-80^{\circ} \mathrm{C}$ until further analysis. Total protein in samples was quantified using bicinchoninic method (Pierce, Rockford, IL). Both plantaris and adipose were analyzed unless otherwise stated. Two rats from each diet ( $\mathrm{CHO}$ and $\mathrm{PRO})$ and each time point (0, 30, and $90 \mathrm{~min}$ ) were run on the same gel for phosphorylated protein and a duplicate gel run for total protein.

\section{Total Akt and Akt Ser473 phosphorylation}

Akt analysis was performed using $30 \mu \mathrm{g}$ whole cell lysates from plantaris and adipose and resolved on $10 \%$ SDS-PAGE. Following transfer, nitrocellulose membranes were probed with either rabbit polyclonal Akt antibody or rabbit polyclonal phospho-Akt antibody specific for ser473 (Cell Signaling Technologies, Danvers, MA). The membrane was washed three times with TBS$\mathrm{T}$ then incubated with HRP labeled goat anti-rabbit IgG (Cell Signaling Technologies, Danvers, MA) for $1 \mathrm{~h}$ at room temperature. The membrane was again washed three times in TBS-T. Labeling was detected with enhanced chemiluminescence for $1 \mathrm{~min}$ and exposed to Kodak Biomax film for 15 s. Quantification of bands was determined via densitometry (Image J; NIH, Bethesda, MD) and activation represented as percent of total protein phosphorylated.

\section{Total p70S6K}

p70S6K analysis was performed using whole cell lysates isolated from plantaris and adipose and resolved on 7.5\% SDS-PAGE. Following transfer the membrane was 
incubated with rabbit polyclonal p70S6K antibody (Bethyl Labs, Montgomery, TX) diluted 1:1500 in Superblock T20 overnight at $4^{\circ} \mathrm{C}$ with gentle rocking. The membrane was washed three times with TBS-T and incubated with HRP labeled goat anti-rabbit IgG diluted 1:1500 for $1 \mathrm{~h}$ at room temperature with gentle rocking. The membrane was again washed three times in TBS-T. Labeling was detected with enhanced chemiluminescence for $1 \mathrm{~min}$ and exposed to Kodak Biomax film for $5 \mathrm{~s}$. Quantification of bands was determined via densitometry and activation represented as percent $\gamma$ and $\beta$ (phosphorylated) subunit compared with total p70S6K subunits $(\alpha+\beta+\gamma)$.

\section{Total and phospho-Erk $\mathbf{1 / 2}$}

Whole cell lysate from plantaris and adipose were resolved on $12 \%$ SDS-PAGE. Following transfer the membrane was blocked with Superblock T20 for 45 min at room temperature with gentle rocking. The membrane was incubated with either rabbit polyclonal p44/42 MAPK antibody or phospho-p44/42 MAPK antibody specific for thr202 and tyr204 (Cell Signaling, Danvers, MA), both diluted 1:1500 in Superblock T20 overnight at $4{ }^{\circ} \mathrm{C}$ with gentle rocking. The membrane was washed three times with TBS-T and incubated with HRP labeled goat anti-rabbit antibody diluted 1:1500 for $1 \mathrm{~h}$ at room temperature with gentle rocking. The membrane was again washed three times with TBS-T. Labeling was detected with enhanced chemilumenescence for $1 \mathrm{~min}$ and exposed to Kodak Biomax film for $15 \mathrm{~s}$. Quantification of bands was determined via densitometry and activation represented as percent of total protein phosphorylated.

\section{Statistical Analysis}

Values are presented as means \pm SEM. Data were analyzed by two-way ANOVA using SPSS Version 15.0 (SPSS Inc., Chicago, IL) with subsequent Tukey posthoc with diet treatment and time points as independent variables. Statistical significance was set at $\mathrm{p}<0.05$.

\section{Results}

\section{Body Weights and Food Intake}

Body weights and food intake were not different between diet treatments. Final body weights were 275.7 $\pm 1.3 \mathrm{~g}$ and $273.7 \pm 1.6 \mathrm{~g}$ in the PRO and CHO treatments, respectively.

\section{Plasma Glucose, Insulin and C-peptide}

Fasting blood glucose in the PRO treatment was $10 \%$ higher than the $\mathrm{CHO}$ treatment (Table 2) which is consistent with previous studies [3]. Plasma glucose response to the meals differed between diet groups. The $\mathrm{CHO}$ treatment exhibited a parabolic shaped curve that increased to a peak at $60 \mathrm{~min} \operatorname{PP}(11.27 \pm 0.66 \mathrm{mmol} / \mathrm{L})$ and decreased to near baseline levels by $120 \mathrm{~min}$, whereas the PRO treatment exhibited an early peak in glucose at $30 \mathrm{~min} P P(9.71 \pm 0.20 \mathrm{mmol} / \mathrm{L})$ and was not different from baseline levels at $60 \mathrm{~min}$. Plasma glucose was significantly higher in the $\mathrm{CHO}$ group compared to the PRO treatment at $60 \mathrm{~min}$.

Consistent with PP plasma glucose concentrations, the insulin and C-peptide curves exhibited different PP response patterns between the diet treatments (Table 2). The PRO treatment produced a PP biphasic insulin response curve with insulin concentrations higher at 30 min PP and 90 min PP, and comparatively decreased at $60 \mathrm{~min}$. PP insulin increased in response to the $\mathrm{CHO}$ meal at $30 \mathrm{~min}$ PP and remained elevated through the $120 \mathrm{~min}$ time course. Diet treatments were significantly different at $60 \mathrm{~min}$. The time-course of insulin release is further characterized by the C-peptide responses (Figure 1).

\section{Total Akt and Akt Ser473 phosphorylation}

Intracellular Akt levels exhibited differential expression in skeletal muscle and adipose depending on the diet treatment. Animals consuming the PRO diet displayed a 2- to 3-fold increase in Akt activation in skeletal muscle at 30 and $90 \mathrm{~min}$ PP $(\mathrm{p}<0.05)$ while the $\mathrm{CHO}$ was not significantly different from baseline (Figure 2). In adipose tissue, the $\mathrm{CHO}$ group exhibited significant elevation of phosphorylated Akt in adipose in response to the meal at $30 \mathrm{~min}$ PP and remained elevated at $90 \mathrm{~min}$ (Figure 3). Animals in the PRO group had delayed activation of Akt elevated only at $90 \mathrm{~min}$ PP.

\section{Total p70S6K}

Meal responses for p70S6K in skeletal muscle were different between treatment groups and similar to Akt responses. The PRO group increased p70S6K activation at $30 \mathrm{~min}$ PP with continued increases at $90 \mathrm{~min}$ PP (Figure 4). Animals consuming the $\mathrm{CHO}$ diet failed to stimulate p70S6K activity in skeletal muscle in response to the meal. The PRO treatment exhibited $12 \%$ and $20 \%$ greater activation of the $\gamma$ (hyperphosphorylated) subunit at 30 and 90 min $(\mathrm{p}<0.05)$ PP respectively compared with the $\mathrm{CHO}$ treatment. P70S6K in adipose tissue was only faintly detected in either diet treatment likely due to insufficient protein extracted during processing (data not shown).

\section{Total Erk and Erk Thr202/Tyr204 (p42/44 MAPK) phosphorylation}

The CHO group exhibited a $22 \%$ increase in Erk $1 / 2$ phosphorylation at $90 \mathrm{~min}$ PP in skeletal muscle (Figure $5)$. This same trend was found in the adipose for the CHO group (Figure 6) with a $23 \%$ increase in phosphorylation at $90 \mathrm{~min}$ PP. Conversely, the PRO group had 
Table 2 Pre and post-meal plasma insulin, glucose and C-peptide of rats consuming a $\mathrm{CHO}$ or PRO diet for ${ }^{10 \mathrm{~d}^{\mathbf{1}}}$

\begin{tabular}{|c|c|c|c|c|c|}
\hline Plasma Measures & Premeal $^{2}$ & Postmeal $^{3} 30 \mathrm{~min}$ & Postmeal $^{3} 60 \mathrm{~min}$ & Postmeal $^{3} 90 \mathrm{~min}$ & Postmeal $^{3} 120 \mathrm{~min}$ \\
\hline \multicolumn{6}{|l|}{ Glucose $(\mathrm{mmol} / \mathrm{L}) \dagger$} \\
\hline $\mathrm{PRO}$ & $6.61 \pm 0.16^{*}$ & $9.71 \pm 0.20$ & $7.38 \pm 0.25^{*}$ & $8.18 \pm 0.33^{*}$ & $8.44 \pm 0.51$ \\
\hline $\mathrm{CHO}$ & $6.00 \pm 0.12$ & $9.35 \pm 0.18$ & $11.29 \pm 0.66$ & $9.74 \pm 0.52$ & $8.26 \pm 0.41$ \\
\hline \multicolumn{6}{|l|}{ Insulin (pmol/L) } \\
\hline PRO & $99.58 \pm 13.65$ & $444.81 \pm 80.68$ & $342.33 \pm 32.80^{*}$ & $480.82 \pm 75.48$ & $396.89 \pm 84.70$ \\
\hline $\mathrm{CHO}$ & $93.43 \pm 13.66$ & $407.58 \pm 92.28$ & $518.35 \pm 61.58$ & $544.23 \pm 101.69$ & $520.28 \pm 103.55$ \\
\hline \multicolumn{6}{|l|}{ C-peptide (nmol/L)† } \\
\hline PRO & $0.68 \pm 0.06$ & $2.52 \pm 0.12$ & $2.10 \pm 0.10^{*}$ & $2.43 \pm 0.15$ & $1.93 \pm 0.15$ \\
\hline $\mathrm{CHO}$ & $0.69 \pm 0.05$ & $2.59 \pm 0.15$ & $2.96 \pm 0.08$ & $2.65 \pm 0.09$ & $2.38 \pm 0.05$ \\
\hline
\end{tabular}

${ }^{1}$ Values are $\pm \mathrm{SEM}, \mathrm{n}=6$

${ }^{2}$ Following $12 \mathrm{~h}$ food deprivation.

${ }^{3}$ Samples collected 30, 60, 90 and 120 min following $4 \mathrm{~g}$ meal.

* $<0.05$ between diet.

$\dagger<0.05$ diet $x$ time interaction.

no significant response to the meal in either skeletal muscle or adipose.

\section{Discussion}

DRI guidelines establish wide ranges of acceptable macronutrient intakes implying that individuals can select healthy intakes at any point within these ranges. However, little is known about metabolic responses, particularly insulin-mediated signaling, at the upper and lower ends of these ranges. The current study demonstrates significant differences in insulin signaling with carbohydrate and protein intakes at the higher and lower ends of the DRI range.

Animals in both the PRO and $\mathrm{CHO}$ treatment groups exhibited PP glycemic responses, however the responses differed between treatments. These glycemic regulations

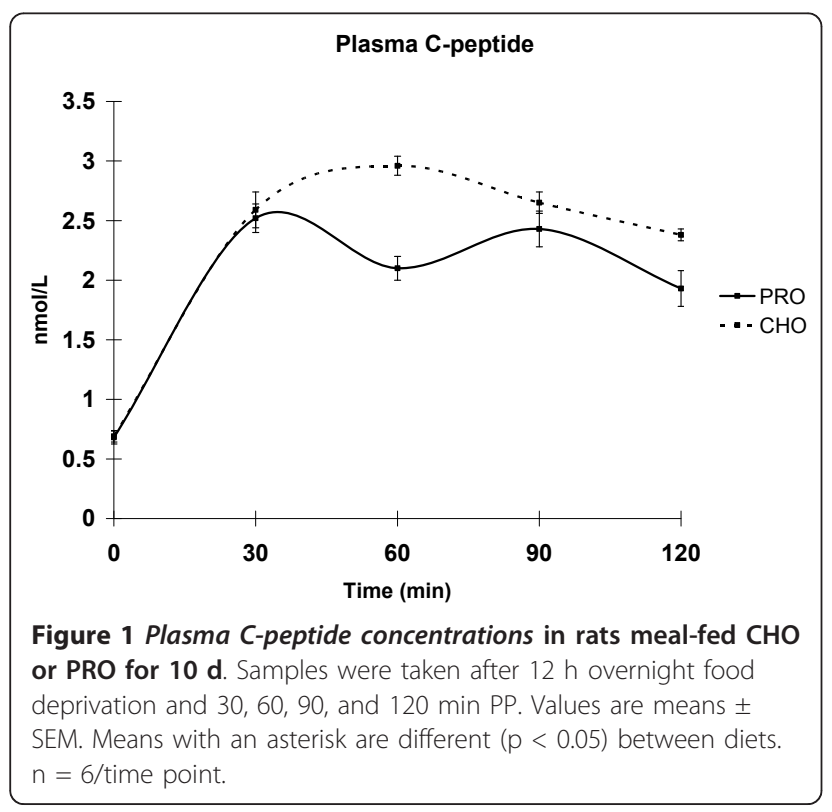

are measured at the systemic level by insulin, glucose and C-peptide, and at the tissue level by Akt, p70S6K, and Erk1/2. Previous studies have shown diets with reduced carbohydrates $(<150 \mathrm{~g} / \mathrm{d})$ and increased protein $(>1.5 \mathrm{~g} / \mathrm{kg})$ improve glycemic regulations in normal [11], obese [12,13] and diabetic [14-18] subjects. This study using phenotypically normal rats also found improved glycemic regultions including reduced PP plasma glucose and enhanced biphasic-like insulin and C-peptide response. The PRO group also had higher fasting blood glucose previously shown to be due to increased hepatic gluconeogenesis and reduced reliance on glycogen [19]. These differences in PP glycemic responses to the diets are expected due to differences in the dietary carbohydrate load, however the increased PP glucose response with the higher carbohydrate diet indicates a shift in focus of insulin signaling from skeletal muscle to adipose tissue to maintain glucose homeostasis [10].

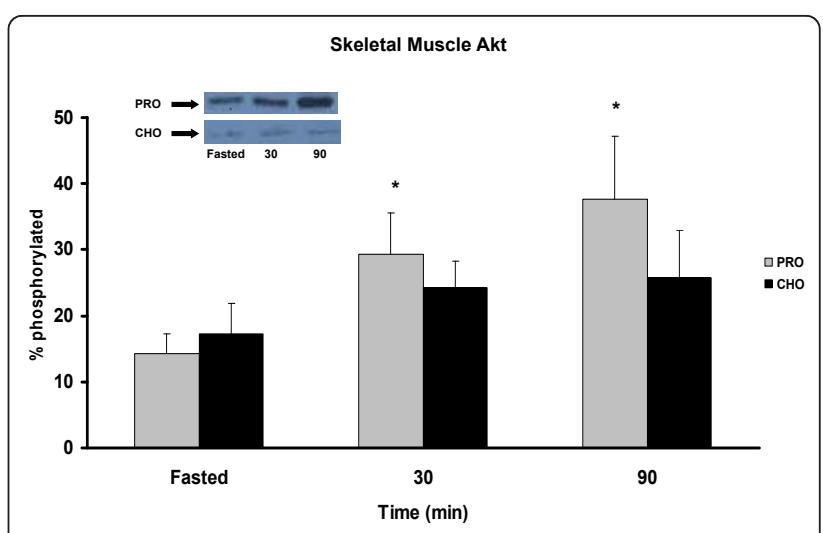

Figure 2 Akt phosphorylation in skeletal muscle pre-meal and 30, 90 min PP in rats meal-fed CHO or PRO for $10 \mathrm{~d}$. Samples were collected after $12 \mathrm{~h}$ overnight food deprivation and 30, $90 \mathrm{~min}$ PP. Values are means \pm SEM. Means with an asterisk are different compared to time $0(p<0.05), n=6 /$ timepoint. 


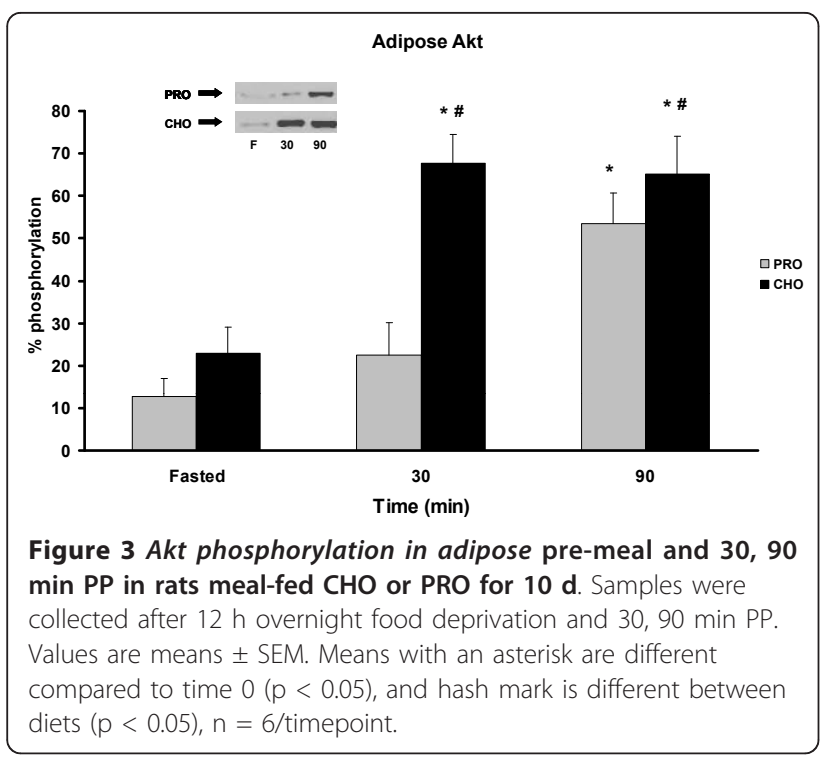

The differences in glycemic regulation are particularly evident during the early period of the insulin response (30 min PP). Classically, the early phase response of plasma insulin corresponds to release of endogenous insulin stores from the pancreas, which is believed to occur in the first 10-20 min PP [20]. However, this classical view is based upon acute-phase glucose stimulated cultured beta cells, and direct glucose infusions into animals and human subjects. When consuming a mixed meal, the bi-phasic response exhibits a lag due to the mechanical digestion required to release the glucose load into systemic circulation. Therefore, it is legitimate to believe the responses observed in this study at $30 \mathrm{~min}$ PP are indicative of

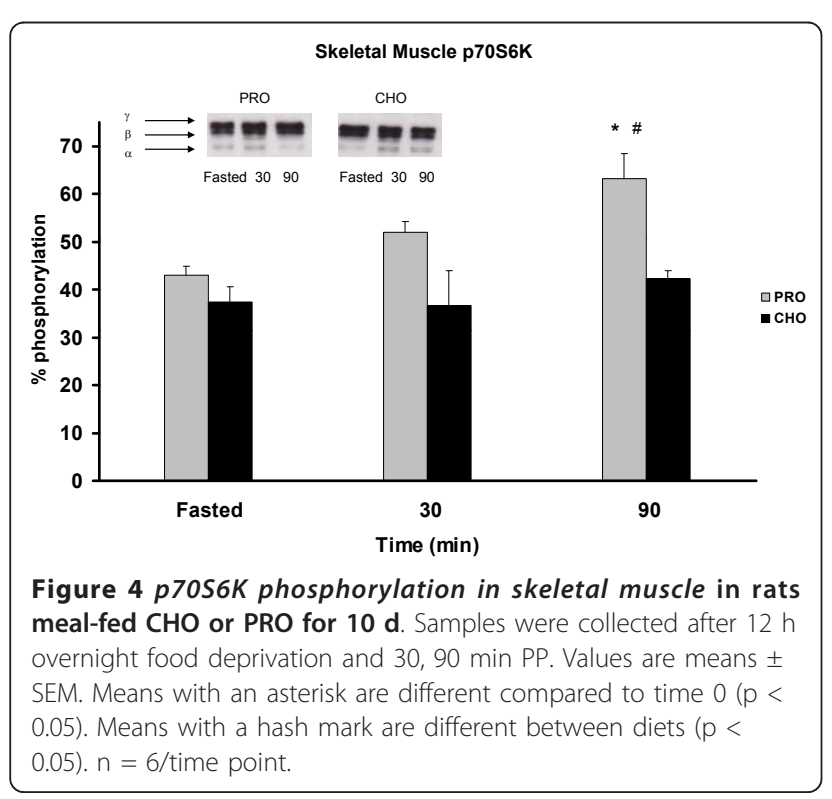

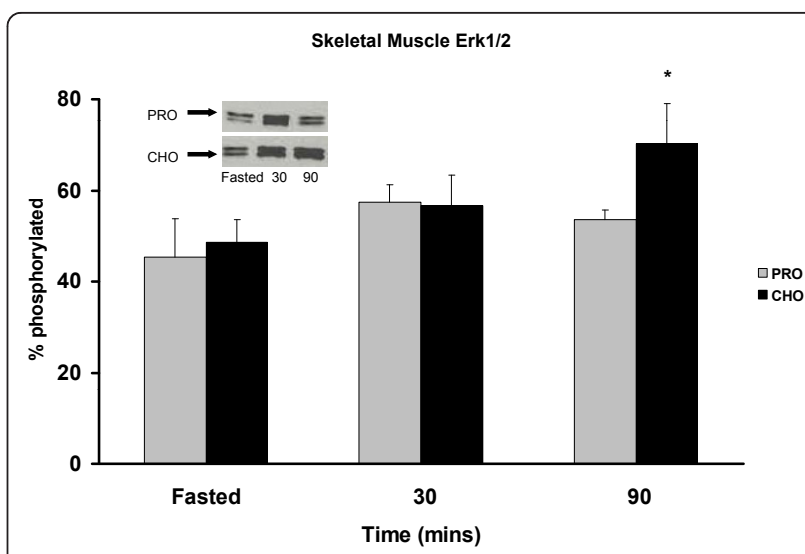

Figure 5 Erk 1/2 phosphorylation in skeletal muscle pre-meal and $30,90 \mathrm{~min}$ PP in rats assigned to $\mathrm{CHO}$ or PRO diet after $10 \mathrm{~d}$ of meal-feeding. Samples were collected after a $12 \mathrm{~h}$ overnight food deprivation and 30, 90 min PP. Values are means \pm SEM. Means with an asterisk are different from time $0(p<0.05)$. $n=6 /$ time point.

an early phase response. The late phase, reflecting insulin concentrations between $60 \mathrm{~min}$ PP, represents newly synthesized insulin in response to circulating glucose concentration from a meal [21]. Insulin responses are often accompanied by $\mathrm{C}$-peptide measures as insulin and $\mathrm{C}$-peptide are released from the beta cell in a 1:1 molar ratio. However, C-peptide has a half-life of $30 \mathrm{~min}$ and little biological activity once released. Thus, it serves to corroborate insulin measurements which can often be skewed by its relatively short half-life of $\sim 5 \mathrm{~min}$ and high metabolic activity. Findings in the present study show similar response patterns between insulin and C-peptide. These

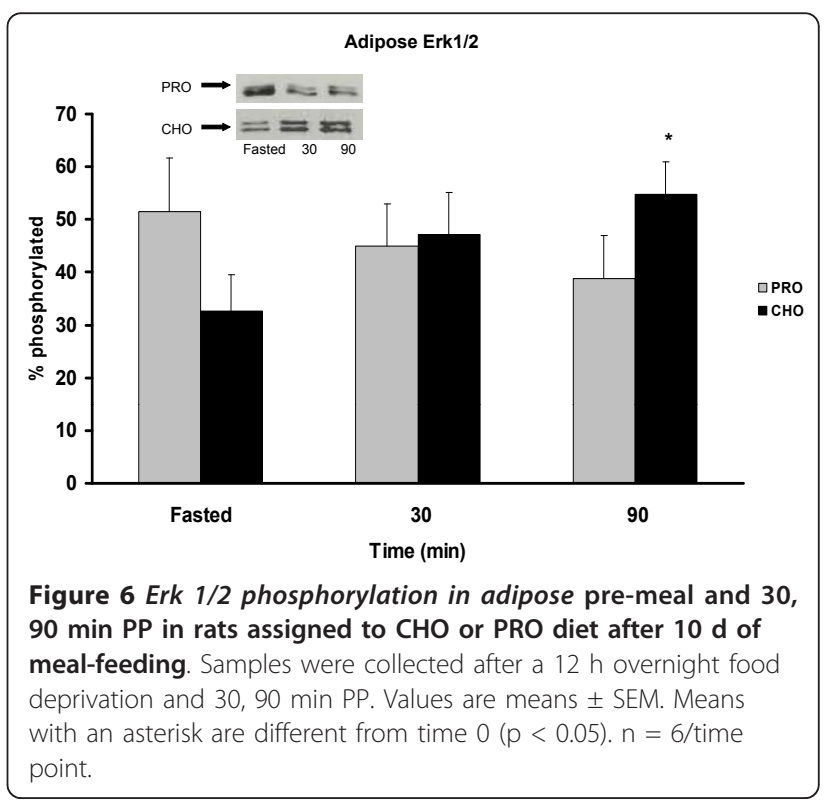


findings suggest Phase I insulin response is largely insensitive to the absolute amount of carbohydrates in the meal, while the second phase appears to be more adaptive. Our data supports this because PP plasma insulin responses in the first $30 \mathrm{~min}$ were not different between the $\mathrm{CHO}$ and $\mathrm{PRO}$ groups $(+331 \mathrm{pmol} / \mathrm{L}$ vs. $+345 \mathrm{pmol} / \mathrm{L}$, respectively) even though the $\mathrm{CHO}$ meal contained $70 \%$ more glucose $(2.4 \mathrm{~g}$ vs. $1.4 \mathrm{~g})$. Comparing these changes in plasma insulin with the amount of carbohydrate in the meal [i.e. insulin concentration $(\mathrm{pmol} / \mathrm{L})$ divided by grams of carbohydrate in the meal], the CHO group had a Phase I insulin response of $130 \mathrm{pmol} / \mathrm{L}$ per grams of dietary glucose at $30 \mathrm{~min}$ PP while the response in the PRO group was $246 \mathrm{pmol} / \mathrm{L}$ per gram of glucose. This blunted response in the $\mathrm{CHO}$ group resulted in elevated plasma glucose at $60 \mathrm{~min}$ PP and a prolonged hyperinsulinemia at $120 \mathrm{~min}$. The prolonged insulin response in the $\mathrm{CHO}$ group is consistent with observations in human studies for subjects fed high carbohydrate diets with similar compositions [5,13].

In addition to different glycemic regulations, altered CHO:PRO ratios created signaling differences in energy sensing metabolic pathways in skeletal muscle and adipose tissues. Akt is an insulin-stimulated upstream signal kinase which triggers release of GLUT4 for glucose transport and downstream activation of protein synthesis via mTOR-mediated p70S6K activation [22]. Surprisingly, the PRO diet produced a greater Akt response in skeletal muscle than the $\mathrm{CHO}$ diet which generated higher PP insulin release. Hence the PRO diet produced a greater Akt response with lower plasma insulin reflecting greater insulin sensitivity in skeletal muscle. This difference was further evident downstream at p70S6K which is sensitive to the insulin signal via Akt and also to amino acid availability via mTOR activation by intracellular leucine [23]. The combination of reduced carbohydrates and increased protein in the PRO diet produced the greatest sensitivity in skeletal muscle Akt and p70S6K signaling. These findings are in agreement with previous reports that glucose uptake into skeletal muscle [3] and muscle protein synthesis [24] are higher in $\mathrm{PRO}$ vs. $\mathrm{CHO}$ diets and consistent with the dysregulation of insulin signaling observed with insulin resistance.

Contrary to the findings in skeletal muscle, the Akt response in adipose was higher for the animals consuming the $\mathrm{CHO}$ diet. At 30 min PP Akt in the $\mathrm{CHO}$ group was approximately 3 -fold higher than the PRO group. Again, this is consistent with report of greater glucose uptake in animals adapted to a $\mathrm{CHO}$ diet [3] and suggests that animals chronically consuming a $\mathrm{CHO}$ diet will preferentially rely on adipose to dispose of excess glucose after a high carbohydrate meal.
Furthermore, Erk $1 / 2$ levels associated with the $\mathrm{CHO}$ diet are increased in adipose. Erk1/2, when elevated, is characteristically a marker of cell growth and division, and recently linked to increases in adipocity [7]. Thus, when taken together, the meal responses of increased Akt levels and increased glucose uptake appear to be shunting glucose disposal into the adipose which may stimulate adiposity via activation of the Erk $1 / 2$ pathway. Contrary to the metabolic pattern of the $\mathrm{CHO}$ diet, the PRO diet decreases Erk1/2 levels in adipose and instead increases p70S6k levels in skeletal muscle consistent with higher protein turnover and greater energy expenditure [25].

\section{Conclusions}

This study demonstrates that while normal animals have the ability to maintain glucose homeostasis across the full range of the DRI AMDR, chronic consumption of a diet with altered CHO:PRO ratios produce different glycemic regulations resulting in different signaling responses in skeletal muscle and adipose. Animals chronically consuming the $\mathrm{CHO}$ diet produced greater metabolic signaling in adipose tissue to handle excess glucose and blunted signaling in skeletal muscle consistent with interpretation of insulin resistance. Conversely, animals consuming the PRO diet produced greater metabolic signaling in skeletal muscle with little signaling in adipose. While these data suggest that consuming an increased CHO:PRO diet may have detrimental effects on insulin sensitivity, the long-term significance of these metabolic differences warrants further investigation.

\section{Abbreviations used}

AMDR: Acceptable Macronutrient Distribution Range; $\mathrm{CHO}$ : increased carbohydrate:protein ratio diet; DRI: Dietary Reference Intakes; Erk1/2: extracellular signal related kinase 1/2; HRP: horseradish peroxidase; MAPK: mitogen activated protein kinase; mTOR: mammalian target of rapamycin; p70S6K: 70-kDa ribosomal protein S6 kinase; PRO: decreased carbohydrate: protein ratio diet; PP: post-prandial; TBS-T: tris buffered saline with tween.

\section{Author details}

${ }^{1}$ Committee on Molecular Metabolism and Nutrition, The University of Chicago, Chicago, IL 60637, USA. ${ }^{2}$ Department of Medicine, The University of Chicago, Chicago, IL 60637, USA. ${ }^{3}$ Division of Nutritional Sciences, University

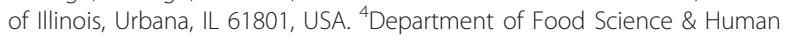
Nutrition, University of Illinois, Urbana, IL 61801, USA.

\section{Authors' contributions}

SD designed study and carried out all experimental procedures and analyses, and drafted the manuscript. DKL helped conceive and design study, edited the manuscript, and approved final submission. All authors have read and approved the final manuscript.

\section{Competing interests}

Supported by grants from the National Dairy Council/DMI and the Illinois Department of Agriculture (CFAR).

Author Disclosures: SD has no conflict of interest; DKL contributes to the NDC and National Cattleman's Beef Association speaker's bureaus, and a nutrition consultant to the Egg Nutrition Center. 
Received: 22 September 2010 Accepted: 4 March 2011

Published: 4 March 2011

\section{References}

1. Farnsworth E, Luscombe ND, Noakes M, Wittert G, Argyiou E, Clifton PM Effect of a high-protein, energy-restricted diet on body composition, glycemic control, and lipid concentrations in overweight and obese hyperinsulinemic men and women. Am J Clin Nutr 2003, 78(1):31-9.

2. Gannon MC, Nuttal FC: Control of blood glucose in type 2 diabetes without weight loss by modification of diet composition. Nutr Metab 2006, 3:16.

3. Baum Jl, Layman DK, Freund GG, Rahn KA, Nakamura MT, Yudell BE: A reduced carbohydrate, increased protein diet stabilizes glycemic control and minimizes adipose tissue glucose disposal in rats. J Nutr 2006, 136:1855-61.

4. Peterson KF, Dufour S, Savage DB, Bilz S, Soloman G, Yonemitsu S, Cline GW, Befroy D, Zemany L, Kahn BB, Papademetris X, Rothman DL, Shulman Gl: The role of skeletal muscle insulin resistance in the pathogenesis of the metabolic syndrome. Proc Natl Acad Sci 2007, 104(31):12587-94.

5. Layman DK, Shiue H, Sather C, Erickson DJ, Baum Jl: Increased dietary protein modifies glucose and insulin homeostasis in adult women during weight-loss. J Nutr 2003, 133:405-10.

6. Blouet C, Mariotti F, Azzout-Marniche D, Bos C, Mathe V, Tome D, Huneau JF: The reduced energy intake of rats fed a high-protein lowcarbohydrate diet explains the lower fat deposition, but macronutrient substitution accounts for the improved glycemic control. J Nutr 2006, 136(7):1849-54.

7. Lee SJ, Pfluger PT, Kim JY, Noguieres R, Duran A, Pages G, Pages G, Pouyssegur J, Tschop MH, Diaz-Meco MT, Moscat J: A functional role for the p62-ERK1 axis in the control of energy homeostasis and adipogenesis. EMBO rep 2010, 11:226-32.

8. Food and Nutrition Board, Institute of Medicine: Dietary reference intakes for energy, carbohydrate, fiber, fat, fatty acids, cholesterol, protein and amino acids. Washington, DC: National Academy Press; 2002.

9. Stoll BA: Western nutrition and the insulin resistance syndrome: A link to breast cancer. Eur J Clin Nutr 1999, 53(2):83-8.

10. Layman DK, Baum J: Dietary protein impact on glycemic control during weight loss. J Nutr 2004, 134(supp):S968-73.

11. Krezowski PA, Nuttal FQ, Gannon MC, Bertosh NH: The effect of protein ingestion on metabolic response an oral glucose in normal individuals. Am J Clin Nutr 1986, 44:847-56.

12. Samaha FF, lqbal N, Seshadri P, Chicano KL, Daily DA, McGrory J, Williams T, Williams M, Gracely EJ, Stern L: A low carbohydrate as compared with a low-fat in severe obesity. N Engl J Med 2003, 348:2074-81.

13. Walker-Lasker DA, Evans EM, Layman DK: Moderate carbohydrate, moderate protein weight loss diet reduces cardiovascular disease risk compared to high carbohydrate, low protein diet in obese adults: A randomized clinical trial. Nutr \& Metab 2008, 5:30-9.

14. Boden G, Sargrad K, Homko C, Mozzoli M, Stein PT: Effect of a lowcarbohydrate diet on appetite, blood glucose levels, and insulin resistance in obese patients with type 2 diabetes. Ann Intern Med 2005, 142:403-11.

15. Gannon MC, Nuttall JA, Damberg G, Gupta V, Nuttall FQ: Effect of protein ingestion on the glucose appearance rate in people with type 2 diabetes. J Clin Endocrinol Metab 2001, 86:1040-7.

16. Gannon MC, Nuttal FQ, Saeed A, Jordan K, Hoover H: An increase in dietary protein improves the blood glucose response in persons with type 2 diabetes. Am J Clin Nutr 2003, 78:734-41.

17. Parker B, Noakes M, Luscombe N, Clifton P: Effect of a high protein, high monounsaturated fat weight loss diet on glycemic control and lipid levels in type 2 diabetes. Diabetes Care 2002, 25:425-30

18. Layman DK, Clifton P, Gannon MC, Krauss RM, Nuttal FQ: Protein in optimal health: heart disease and type 2 diabetes. Am J Clin Nutr 2008, 87:1571S-75S.

19. Rosetti L, Rothman DL, DeFronzo RA, Shulman Gl: Effect of dietary protein on in vivo insulin action and liver glycogen repletion. Am J Physiol 1989, 257(2):E212-19.

20. Nesher R, Cerasi E: Modeling phasic insulin release: immediate and timedependent effects of glucose. Diabetes 2002, 1(supp):53-59.
21. Vilsbøll T, Krarup T, Madsbad S, Holst JJ: Defective amplification of the late phase insulin response to glucose by GIP in obese Type II diabetic patients. Diabetologia 2002, 45(8):1111-9.

22. Manning B, Cantley L: AKT/PKB signaling: navigating downstream. Cell 2007, 129(7):1261-74

23. Harris TE, Lawrence JC: TOR signaling. Science 2003, 212:re15.

24. Norton LE, Layman DK: Leucine regulates translation initiation of protein synthesis in skeletal muscle after exercise. J Nutr 2006, 136(2):533S-37S.

25. She P, Reid TM, Bronson SK, Vary TC, Hajnal A, Lynch CJ, Hutson SM: Disruption of BCATm in mice leads to increased energy expenditure associated with the activation of a futile protein turnover cycle. Cell Metab 2007, 6(3):181-94.

doi:10.1186/1743-7075-8-13

Cite this article as: Devkota and Layman: Increased ratio of dietary carbohydrate to protein shifts the focus of metabolic signaling from skeletal muscle to adipose. Nutrition \& Metabolism 2011 8:13.

\section{Submit your next manuscript to BioMed Central and take full advantage of:}

- Convenient online submission

- Thorough peer review

- No space constraints or color figure charges

- Immediate publication on acceptance

- Inclusion in PubMed, CAS, Scopus and Google Scholar

- Research which is freely available for redistribution

Submit your manuscript at www.biomedcentral.com/submit
Ciomed Central 